\title{
Long-term dynamics of monoterpene synthase activities, monoterpene storage pools and emissions in boreal Scots pine
}

\author{
Anni Vanhatalo ${ }^{1}$, Andrea Ghirardo ${ }^{2}$, Eija Juurola ${ }^{1,3}$, Jörg-Peter Schnitzler ${ }^{2}$, Ina Zimmer ${ }^{2}$, Heidi Hellén ${ }^{4}$, \\ Hannele Hakola $^{4}$, and Jaana Bäck ${ }^{1}$ \\ ${ }^{1}$ Institute for Atmospheric and Earth System Research/Forest Sciences, Faculty of Agriculture and Forestry, \\ P.O. Box 27, 00014 University of Helsinki, Helsinki, Finland \\ ${ }^{2}$ Helmholtz Zentrum München, Research Unit Environmental Simulation, Institute of Biochemical \\ Plant Pathology, 85764 Neuherberg, Germany \\ ${ }^{3}$ ICOS ERIC Head Office, Erik Palménin aukio 1, 00560 Helsinki, Finland \\ ${ }^{4}$ Finnish Meteorological Institute, P.O. Box 503, 00101 Helsinki, Finland
}

Correspondence: Anni Vanhatalo (anni.vanhatalo@helsinki.fi)

Received: 11 January 2018 - Discussion started: 26 January 2018

Revised: 4 July 2018 - Accepted: 20 July 2018 - Published: 24 August 2018

\begin{abstract}
Seasonal variations in monoterpene emissions from Scots pine (Pinus sylvestris) are well documented, and emissions are often shown to follow the incident temperatures due to effects on compound volatility. Recent studies have indicated a link between monoterpene emissions and physiological drivers such as photosynthetic capacity during needle development. The complex interplay between the dynamic changes in the biosynthetic capacity to produce monoterpenes and the temperature-dependent evaporation process of volatiles from internal storage reservoirs has not yet been studied under field conditions.

In this study, we analysed the relationships between needle monoterpene synthase activities, endogenous monoterpene storage pools and monoterpene emissions of needles in two consecutive years at a boreal forest site in Finland.

The results showed changes in the monoterpene synthase activity of needles, linked to seasonality and needle ontogenesis, while the pool of stored monoterpenes (about $0.5 \%$ of dry weight) did not change considerably as a function of needle aging. Monoterpene emissions did not correlate directly with enzyme activity or the storage pool size. We observed notably high plant-to-plant variation in the biosynthesis rates of individual monoterpenes, which did not reflect the storage compound mixture. The enzyme activity producing $\delta$ 3 -carene was only present in the first months after needle flushing, and decreased with needle age, whereas $\delta$-3-carene
\end{abstract}

was abundant in the endogenous monoterpene pool and dominated the needle emissions.

This study emphasizes the seasonal, developmental and intraspecific variability of monoterpene biosynthesis and storage, and calls for more in-depth analyses to reveal how such complex interaction affects monoterpene emissions from pine needles in boreal forests.

\section{Introduction}

The evergreen foliage of conifers needs to acclimate to severe stresses under boreal winter conditions, including low minimum temperatures, low light availability and repeated freeze-thaw cycles. This acclimation is manifested in both structural and metabolic adjustments of needles. Seasonal dynamics in many plant processes creates strong variations in metabolic pools that enable the needles to remain viable and retain their functional capacity when conditions improve (e.g. Porcar-Castell et al., 2008; Ensminger et al., 2004, 2006). The spring dehardening of coniferous trees is closely linked to physiological changes related to the onset of growth, whereas hardening in the autumn results from the gradual downregulation of cellular metabolism, largely triggered by changes in temperature and the light environment (Hänninen and Tanino, 2011). In addition to primary metabolism related to growth and development, the sec- 
ondary metabolism of needles, including the synthesis of volatile compounds, also shows a seasonal pattern that reflects their physiological state (e.g. Fischbach et al., 2002; Jaakola and Hohtola, 2010).

In coniferous plant species, volatile terpenes are produced in all tissues (needles, sapwood, bark, roots) and stored either in specialized terpene storage structures, the resin ducts (Loreto and Schnitzler, 2010), or in non-specific storage pools, for example cell membranes (Niinemets and Reichstein, 2002, 2003a, b; Ormeño et al., 2011). The regulation of terpene biosynthesis in needles is a complex process controlled by the availability of carbon substrates, as well as by the energy status of the cell (energy and redox equivalents) and key regulatory enzyme activities (Bohlmann et al., 1998; Fischbach et al., 2002; Dudareva et al., 2004; Ghirardo et al., 2014; Wright et al., 2014). Conversely, the turnover rates of storage pools depend on environmental constraints (primarily temperature) and on physiological or stress-related processes (e.g. filling of the resin duct storage; herbivoryinduced plant defence responses). However, understanding of synthesis and storage pool dynamics is rather limited. Labelling experiments under laboratory conditions have revealed that monoterpene biosynthesis in needles is closely linked to the incident photosynthetic carbon supply in many conifer species. It has been shown that $30 \%-60 \%$ of emitted monoterpenes originate from recently fixed carbon, comprising the so-called "de novo" emissions, as opposed to the emissions from permanently stored pools (Loreto et al., 2000b; Ghirardo et al., 2010, 2011, 2014).

Large seasonal variations in volatile organic compound (VOC) emission rates and also in the blend of emitted compounds have often been reported from coniferous trees such as Scots pine (Pinus sylvestris L.) (e.g. Janson, 1993; Komenda and Koppmann, 2002; Tarvainen et al., 2005). In the summer, VOC emissions are generally highest due to correspondingly high temperatures, but under boreal conditions the monoterpene emission rates of Scots pine foliage are also quite high in spring, whereas sesquiterpenes are mainly emitted during the summer period (e.g. Tarvainen et al., 2005; Hakola et al., 2006; Aalto et al., 2014). One hypothesis for such high seasonal variability is that volatile terpenes may, in addition to their multiple other functions, protect cells from excess energy during periods when photosynthesis is depressed (e.g. Loreto and Velikova, 2001; Owen and Penũelas, 2005; Loreto and Schnitzler, 2010; Velikova et al., 2014; Aalto et al., 2015). In addition to the seasonal fluctuations, high levels of variation exist between and within trees. Buds and young growing needles are a significant source of VOC emissions during spring dehardening and shoot elongation, and their emission rates can be 1-2 orders of magnitude higher than those of older needle age classes (Aalto et al., 2014). Moreover, individual pine and spruce trees produce and emit conspicuous, tree-specific monoterpene blends (Schönwitz et al. 1990a; Bäck et al., 2012; Hakola et al., 2017).
As previously shown in the case of high emissions from emerging foliage (Aalto et al., 2014), phenology is an important driver for seasonal monoterpene dynamics (e.g. Wiß et al., 2017), not only in deciduous plant species but also in evergreens, which retain their foliage for several years. In evergreens, the development of new buds and foliage occurring in spring is characterized by conspicuously high emissions of monoterpenes, methanol and some other VOCs (Aalto et al., 2014). However, long-term studies clarifying the seasonality of monoterpene production and storage in evergreen foliage are scarce, and their correlations with needle emissions have not yet been studied under field conditions. Fischbach et al. (2002) detected strong changes in holm oak (Quercus ilex, non-storing species) monoterpene synthase activities as leaves developed and aged. Thoss et al. (2007) observed a chemotype-specific change in the relative composition of monoterpene storage in developing Scots pine needles. However, no consistent seasonal response of stored terpene concentrations was found in Aleppo pine (Pinus halepensis Mill.) or three other Mediterranean woody plants in response to drought and warming (Llusià et al., 2006). Litvak et al. (2002) found no relationship between monoterpene storage pool sizes and synthase activities of Douglas fir (Pseudotsuga menziesii). Therefore, a reasonable question is how the phenology, seasonality and environmental stimuli affect the production, storage and emission of monoterpenes, and to what extent they are interrelated.

The present work was designed to comprehensively examine the linkages and dynamics of seasonal monoterpene emissions with the corresponding in vitro enzyme activities and sizes of storage pools in Scots pine needles in situ in a boreal forest. Because needle development (flushing, maturation and gradual ageing) was anticipated to affect the production, storage pools and emissions of monoterpenes, we followed the same branches over two consecutive years to examine possible relationships between the developmental state of needles, monoterpene emission rates, storage pool sizes and monoterpene synthase activities.

\section{Materials and methods}

\subsection{Site description}

The samples were collected from the SMEAR II measurement station (Station for Measuring Ecosystem-Atmosphere Relations) in southern Finland, in a 50-year-old Scots pine forest during 18 months between winter 2009 and summer 2010. The site is located in a managed boreal forest $\left(61^{\circ} 51^{\prime} \mathrm{N}, 24^{\circ} 17^{\prime} \mathrm{E}, 181 \mathrm{~m}\right.$ a.s.l.). The forest was regenerated by seeding after a prescribed burning in 1962 . The site was thinned once, in 2002, its density is 1075 trees ha $^{-1}$ and its leaf area index is $3.5 \mathrm{~m}^{2} \mathrm{~m}^{-2}$ (Ilvesniemi et al., 2009). The annual mean temperature at the site is $3.5^{\circ} \mathrm{C}$ and the annual precipitation is $711 \mathrm{~mm}$ (Pirinen et al., 2012). 
Table 1. Details of the trees examined and the sampling.

\begin{tabular}{lrrrr}
\hline Tree \# & $\begin{array}{r}\text { Height } \\
(\mathrm{m})\end{array}$ & $\begin{array}{r}\text { Diameter at } \\
1.3 \mathrm{~m}(\mathrm{~cm})\end{array}$ & $\begin{array}{r}\text { Number of } \\
\text { needle } \\
\text { samples }\end{array}$ & $\begin{array}{r}\text { Number of } \\
\text { emission } \\
\text { samples }\end{array}$ \\
\hline 1 & 17.7 & 16.6 & 4 & 1 \\
2 & 17.9 & 18.4 & 4 & 1 \\
3 & 17.6 & 17.3 & 21 & 15 \\
4 & 17.8 & 18.6 & 40 & 1 \\
\hline
\end{tabular}

The height of dominant trees is $18 \mathrm{~m}$, with a breast height diameter of $20 \mathrm{~cm}$. The typical annual tree stem growth rate is $8 \mathrm{~m}^{3} \mathrm{ha}^{-1}$ (Vesala et al., 2005). The station is equipped with a comprehensive set-up for continuous monitoring of tree and forest floor gas exchange and the relevant environmental, atmospheric chemistry and physical variables (for a detailed description, see Hari and Kulmala, 2005).

\subsection{Sampling}

The temporal patterns of monoterpene emissions, synthesis and pools were analysed with a repeated sampling design from four Scots pine trees (\#1 to \#4) located a few metres from each other. Needle samples were collected from sunexposed, healthy upper canopy branches of the trees, which were accessible from a scaffolding tower. On each sampling occasion, six healthy needle pairs from three branches (whorls 3 to 5, about 1-2 m below treetop) were collected and pooled as one sample per tree. Samples from two needle age classes, formed during summer 2008 (hereafter referred to as "2008 needles") and 2009 ("2009 needles"), were collected separately and wrapped in aluminium foil. The samples were immediately frozen in a container of liquid nitrogen and kept at $-80^{\circ} \mathrm{C}$ until grinding under liquid nitrogen cooling for further biochemical analysis. Two trees (\#3 and \#4) were intensively sampled between February 2009 and July 2010 , generally one to three times per month, with the shortest sampling interval occurring during the transient developmental phase in spring (42 sampling days in total, Fig. 1 and Table 1). Additionally, two other trees (\#1 and \#2) were sampled four times between September 2009 and June 2010 to better understand the tree-to-tree variability in the measured parameters.

Emissions from all four trees were tested before the campaign in order to examine whether they differed from each other regarding their emission spectrum (see Bäck et al., 2012). Monoterpene emissions were measured in August 2009 from all four trees. Due to limited resources, this was the only time period when all trees could be sampled at the same time. Tree \#3 was monitored more intensively: its emissions were measured a total of 15 times between February 2009 and June 2010. The emission monitoring was always carried out from the same upper canopy branch with a transparent FEP (fluorinated ethylene propylene) foil- covered dynamic flow-through shoot chamber (volume approximately $6 \mathrm{~L}$, see Fig. 2a; further details, e.g., in Hakola et al., 2006). The whole shoot, i.e. both 2008 and 2009 needles as well as woody twigs, was enclosed in the chamber. The dry weight (DW) of the enclosed needles was about $3 \mathrm{~g}$ (final DW was determined later by drying at $80^{\circ} \mathrm{C}$ after all measurements had been completed). The terminal bud was removed well before the first sampling to avoid emissions from growing tissues and changes in the biomass in the enclosure between measurements. As the settling time here was considerably longer than the period of debudding-induced increased emissions in earlier studies (e.g. Hakola et al., 2006), increased emissions were unlikely to have occurred once the sampling started.

Emitted monoterpenes were collected for $60 \mathrm{~min}$ in adsorbent tubes filled with Tenax-TA/Carbopack-B (200 and $130 \mathrm{mg}$, respectively), with flow rates of approximately $4 \mathrm{~L} \mathrm{~min}^{-1}$ through the chamber and $60 \mathrm{~mL} \mathrm{~min}^{-1}$ through the adsorbent tubes. The air entering the chamber passed through a $\mathrm{MnO}_{2}$ ozone scrubber and an active charcoal cartridge. Photosynthetically active radiation (PAR) and the temperature of the shoot chamber were measured with quantum sensors (LI-190SZ, LI-COR Biosciences, Lincoln, USA) and thermocouples, respectively.

Needle and shoot length growth was measured from adjacent trees at the same site, and the data were utilized to determine the needle development. For the purpose of analysis, needle age (days) was set to zero on the day when needles attained $50 \%$ of their final length. This was 27 June 2008 and 29 June 2009 for the 2008 and 2009 needles, respectively. Figure $2 \mathrm{~b}-\mathrm{e}$ present the growth of the shoot and needles in May (when the growth of shoots had just started, but new needles had not yet emerged), June (the growth of new needles had initiated), July (needles already existed and were used for sampling) and August (fully mature shoot and needles).

\subsection{Analyses of monoterpene synthase activities and storage pool levels}

Monoterpenes stored within the needles (endogenous monoterpene contents) and in vitro enzyme activities of monoterpene synthases (MTS) were analysed from the sampled needles of four pines. The analysis of monoterpene storage pools followed the methods introduced in Fischbach et al. $(2000,2002)$ and further developed in Ghirardo et al. (2010). One millilitre of pentane was added as a solvent to $50 \mathrm{mg}$ of frozen needles. The following changes were made to the methods: after pentane extraction of ground frozen samples, $1 \mu \mathrm{L}$ of the sample was directly injected and analysed using a thermo-desorption (TD) unit (TDU, Gerstel $\mathrm{GmbH}$ ) coupled to a gas chromatograph-mass spectrometer (GC-MS) (GC type: 7890A, MS type: 5975C inert XL MSD with a triple axis detector, both from Agilent Technologies, Palo Alto, CA, USA) using a $5 \%$ phenyl $95 \%$ dimethyl 


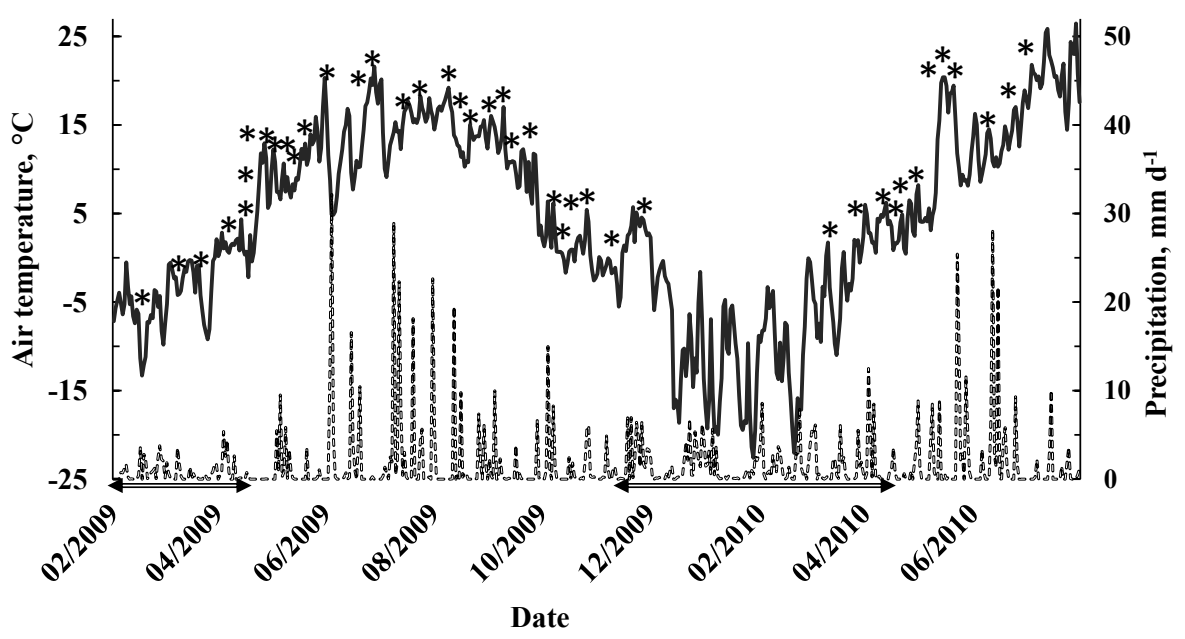

Figure 1. Daily mean air temperature (solid line) and daily precipitation (dashed line) at the sampling site during the sampling period from February 2009 to July 2010. Stars indicate the sampling dates (not all the trees were sampled every time). Horizontal arrows represent the snow cover periods.
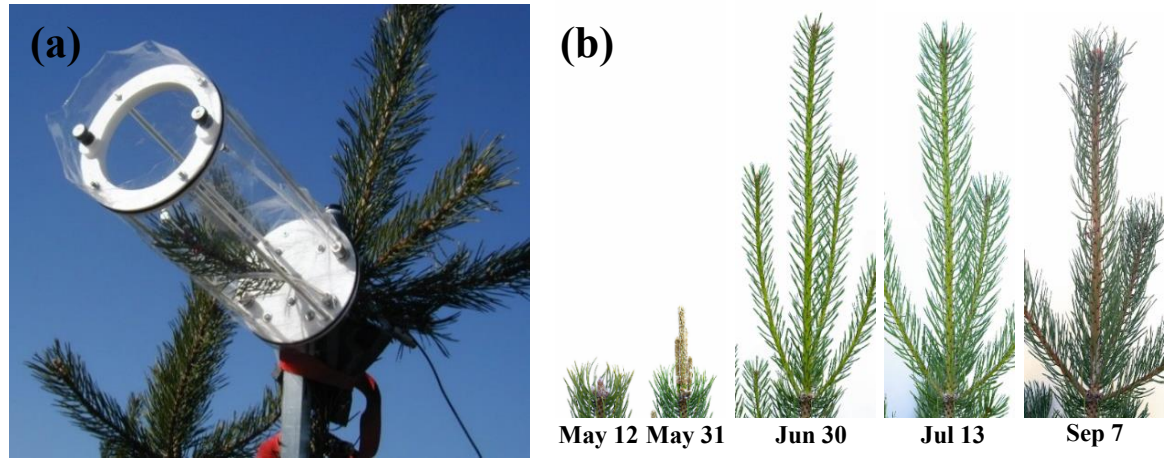

Figure 2. (a) Emission measurements were performed with a transparent shoot chamber, which is here shown open between samplings. (b) Development of a new shoot in Scots pine in 2010. Sampling of new needles started in early July. Photos: Juho Aalto.

arylene siloxane capillary column $(60 \mathrm{~m} \times 250 \mu \mathrm{m} \times 0.25 \mu \mathrm{m}$ DB-5MS + $10 \mathrm{~m} \mathrm{DG}$, Agilent Technologies). The TD-GCMS was run as previously described (Ghirardo et al., 2012).

Analysis of in vitro MTS activities was carried out as per the description in Ghirardo et al. (2012). Briefly, proteins were extracted and successively incubated for $60 \mathrm{~min}$ with non-polar, polydimethylsiloxane (PDMS)-coated stir bars (twisters, film thickness of $0.5 \mathrm{~mm}$, Gerstel $\mathrm{GmbH}$ ) together with the enzyme substrate geranyl diphosphate (GPP). Enzymatically produced monoterpenes were trapped from the aqueous reaction solution by the twisters, and the removal of the stir bars terminated the assays. After rinsing in deionized water, the twisters were analysed using TD-GCMS. Each sample was analysed with three technical replicates. Enzyme activities were only assessed for the samples with protein contents higher than $0.1 \mathrm{mg} \mathrm{mL}^{-1}$, and were otherwise recorded as missing values. Calibration was achieved by injecting pure substances into hexane at different concentrations (6-600 pmol $\mu \mathrm{L}^{-1}$ ) as previously described (Kreuzwieser et al., 2014).

A total of 12 different monoterpenes and their derivatives could be detected from the extracts: $\alpha$-pinene, camphene, sabinene, $\beta$-pinene, $\beta$-myrcene, $\delta$-3-carene, geraniol, linalool, linalool oxide, trans- $\beta$-ocimene, $\gamma$-terpinene and tricyclene. However, most of these compounds were only present as traces; therefore, only the major monoterpenes, $\alpha$ pinene, $\beta$-pinene, camphene and $\delta$-3-carene, which together account for $>90 \%$ of the storage pool, were included in the subsequent analysis. Both assays, (i) analysis of storage pools and (ii) MTS activities, were performed with frozen needle material (fresh weight, FW). For comparison with monoterpene emission rates, the data were normalized to dry weight (DW) using the DW/FW ratios of 0.37 and 0.48 for the newly formed needles and all other needles, respectively (ratios obtained from corresponding measurements of adjacent trees). 


\subsection{Emission analysis}

The adsorbent tubes were analysed in the laboratory using a thermal desorption instrument (Perkin-Elmer TurboMatrix 650, Waltham, USA) attached to a GC (PerkinElmer Clarus 600, Waltham, USA) with a DB-5MS (60 m, $0.25 \mathrm{~mm}, 1 \mu \mathrm{m})$ column and a mass selective detector (Perkin-Elmer Clarus 600T, Waltham, USA). Five-point calibration was performed using liquid standards in methanol solutions. The detected monoterpenes were $\alpha$-pinene, camphene, $\beta$-pinene, $\delta$-3-carene, $p$-cymene, limonene and terpinolene. The method has been previously described, e.g. in Hellén et al. (2012).

The emission rates $\left(E, \mathrm{mg} \mathrm{kg}^{-1} \mathrm{DW} \mathrm{h}^{-1}\right)$ were calculated using the concentration difference between the air entering and leaving the chamber as follows:

$E=\left[\left(C_{\text {out }}-C_{\text {in }}\right) F\right] / M_{\text {DW }}$,

where $C_{\text {out }}$ and $C_{\text {in }}$ are the monoterpene concentrations $\left(\mathrm{g} \mathrm{L}^{-1}\right)$ of outgoing and incoming air, respectively, $F\left(\mathrm{~L} \mathrm{~h}^{-1}\right)$ is the flow through the chamber and $M_{\mathrm{DW}}$ is the dry needle mass $(\mathrm{g})$ enclosed in the chamber. The monoterpene emission potential (standard emission factor) was obtained using the equation by Guenther (1997) with a $\beta$ value of $0.09 \mathrm{~K}^{-1}$ (frequently used value for Scots pine, e.g. in Hakola et al., 2006; Aalto et al., 2015) and a standard temperature of $30^{\circ} \mathrm{C}$. The air temperature ranged between -3.5 (March 2009) and $22.4^{\circ} \mathrm{C}$ (May 2010) during the emission samplings. Results are given in $\mathrm{m} \mathrm{kg}^{-1} \mathrm{DW}$ or $\mathrm{mg} \mathrm{kg}^{-1} \mathrm{DW} \mathrm{h}^{-1}$ to enable comparisons between synthase activity, storage and emissions.

\subsection{Ancillary data from the site}

To explain the variance in monoterpene dynamics, a large amount of auxiliary data from the same measurement site was employed. Pine foliage net carbon assimilation and transpiration is continuously monitored at the site with automated shoot enclosures, as described, e.g., in Altimir et al. (2002) and Aalto et al. (2015). For this study, running averages were calculated of daytime (PAR $>50 \mu \mathrm{mol} \mathrm{m}^{-2} \mathrm{~s}^{-1}$ ) carbon assimilation and transpiration for one week preceding needle sampling. Needle and shoot length growth were measured from photographs one to three times per week over the growing period and interpolated for the remaining days as presented in Aalto et al. (2014). Needle age was calculated as the time (days) since half of the final needle length had been acquired. A proxy for needle photosynthetic acclimation $(S)$ was calculated with the following dynamic model (Mäkelä et al., 2004):

$\frac{\mathrm{d} S}{\mathrm{~d} t}=\frac{1}{\tau}(T-S)$,

where $T$ is the daily mean air temperature and $\tau$ is a time constant (h). The parameter $S$ was calculated with two time constants: 60 and $200 \mathrm{~h}$ for $S$ and $S 2$, respectively.
Table 2. The variables used in PCA.

\begin{tabular}{ll}
\hline Abbreviation & Variable description \\
\hline$A$ & Pine shoot $\mathrm{CO}_{2}$ assimilation \\
$E$ & Pine shoot $\mathrm{H}_{2} \mathrm{O}$ transpiration \\
$n$ & Needle growth \\
$s$ & Shoot growth \\
age & Needle age \\
PAR & Daily maximum of photosynthetically \\
& active radiation \\
$T_{\text {mean }}$ & Daily mean air temperature \\
$T_{\text {max }}$ & Daily maximum air temperature \\
$T_{\text {min }}$ & Daily minimum air temperature \\
$T_{\mathrm{r}}$ & Daily temperature range \\
$T_{\mathrm{S}}$ & Cumulative temperature sum \\
$T_{\text {soil }}$ & Soil temperature \\
$S 2$ & Proxy for needle photosynthetic \\
& acclimation \\
snow & Snow depth \\
rain & Daily precipitation \\
rainy & Rain indicator \\
VWC & Soil volumetric water content \\
\hline
\end{tabular}

Air temperature at a height of $4.2 \mathrm{~m}$ was measured with a ventilated and shielded Pt-100 sensor and soil temperature with thermistors (Philips KTY 81-110, Philips Semiconductors, Eindhoven, the Netherlands) at five locations. The daily air temperature range was calculated as the difference between daily minimum and maximum temperatures. The temperature sum was calculated as the annual cumulative temperature sum of daily mean air temperatures exceeding $5^{\circ} \mathrm{C}$. The soil volumetric water content $\left(\mathrm{m}^{3} \mathrm{~m}^{-3}\right)$ in the mineral soil B horizon was recorded with time domain reflectometers (TDR 100, Campbell Scientific Inc., Logan, USA) and spatially averaged over five plots at the site. Photosynthetically active radiation (PAR, $\mu \mathrm{mol} \mathrm{m}{ }^{-2} \mathrm{~s}^{-1}$ ) was monitored above the canopy with an LI-190SZ quantum sensor (LI-COR Biosciences, Lincoln, USA). Snow depth was recorded once a week as an average of five plots at the site. Precipitation was monitored with a tipping bucket rain gauge (Vector ARG100 , Vector Instruments, Rhyl, UK). A rain indicator showed whether there had been rain during the sampling day. The weather conditions (daily mean, minimum and maximum air temperature, daily precipitation and snow depth) during the sampling period were measured as part of the standard measurement set-up at the station and are illustrated in Fig. 1.

\subsection{Statistics}

Principal component analysis (PCA) was employed to assess whether the variations in MTS activity, storage and emission could be attributed to changes in physical and physiological conditions, such as seasonal changes in the weather (spring-summer-autumn), needle ontogenesis (aging of the needles) and physiological parameters (needle and shoot 
growth, net $\mathrm{CO}_{2}$ assimilation and transpiration rates). The tree-to-tree variation was not included in the PCA, as the datasets for different trees were not equal in extent. Thus, the analysis was only applied to the dataset of tree \#3 plus the ancillary data. Datasets from 2009 and 2010 were analysed separately in order to better understand the dynamics related to needle age. The correlation between monoterpene emissions, storage pools, MTS activities (compoundspecific), climatic variables, gas exchange and tree physiology data (Table 2) was evaluated using the PCA tools of SIMCA-P (v13, Umetrics, Umeå, Sweden). Thereby, established procedures to analyse MS data were followed as previously reported (Ghirardo et al., 2005, 2012; Velikova et al., 2015). Overall, the matrix was formed by $31 \times 36$ (variables $\times$ observations). Prior to PCA analysis, all variables were logarithmically $(\log 10)$ transformed and centred, and each type of data was block-wise scaled with $1 \mathrm{SD}^{-1}$. Calculated significant principal components were validated using "full cross-validation", with the $99 \%$ confidence level of parameters and seven cross-validation groups.

\section{Results}

\subsection{Needle age and seasonal effects on monoterpene synthase activities, storage and emissions}

We examined the effect of seasonality and needle age on monoterpene synthase (MTS) activity, monoterpene storage pools and emissions in detail, and found that MTS activities were highly dependent on needle age and season (Figs. 3, 4). Specifically, the youngest needles, i.e. the needles born in 2009 and measured in their first summer and autumn, showed high in vitro MTS activities (Figs. 3a, 4a). In particular, $\delta$-3carene dynamics appeared to be strongly related to needle age: this compound was synthesized in greater amounts in the needles only during their growth and maturation (Fig. 4). The highest MTS activities were measured in the early spring (February-March), independent of needle age (Fig. 3a). A gradual decrease in MTS activities was observed in the second summer of the needles (with a similar decrease in needles born in 2008 and 2009 in their second summer). Consistently, the lowest MTS activities (less than $10 \%$ of the maximum) were measured in their third year (when needle age was $>600$ days, i.e. in 2010; Fig. 3a). Exceptions to this age-specific and seasonal pattern were two individual samples with high MTS activities (e.g. 2008 needles sampled on 19 October 2009 and 4 May 2010), possibly indicating that the MTS activities were occasionally triggered by abiotic or biotic stresses (although the sampled needles were visually intact).

The pool size of the endogenous (stored) monoterpenes remained much more constant throughout the measurement period and was independent of the needle age (Fig. 3b). The mean monoterpene storage pool sizes were $4.50 \pm 1.03$ and $4.86 \pm 1.22 \mathrm{~g} \mathrm{~kg}^{-1} \mathrm{DW}$ for the young (<1-year-old) needles and the older needles, respectively. Overall, the amounts of stored monoterpenes in needles ranged between 1.9 and $8.1 \mathrm{~g} \mathrm{~kg}^{-1}$, with only slightly lower values in winter. The storage pools included $31 \% \delta$-3-carene on average $(25 \%$ $42 \%$ in trees \#3 and \#4), but across all measurement dates, $\alpha$-pinene was the main monoterpene in pools (54\%-69\% in trees \#3 and \#4). The temporal variation in storage size mostly resulted from variations in $\alpha$-pinene concentrations.

The highest monoterpene emission rates (up to $6 \mathrm{mg} \mathrm{kg}^{-1} \mathrm{DW} \mathrm{h}^{-1}$, Fig. 3c) from intensively sampled tree \#3 were observed at the end of June 2009. The lowest emission rates were detected in spring 2010, when the oldest needles in the shoot chamber were already 3 years old. The highest emission potentials (standardized to $30^{\circ} \mathrm{C}$ ), in comparison, were observed in early spring and autumn (Fig. 3d).

Overall, neither the synthesis rates nor the emission rates directly correlated with the size of the monoterpene pools across the whole measured period (Fig. 4). All four major monoterpenes showed high variability in their associations between storage pools and synthase activities or emissions. For a given storage pool size, the MTS activities varied by several orders of magnitude, with highest MTS activities present in < 1-year-old needles (Fig. 4a-d).

Therefore, principal component analysis (PCA) was employed to examine the complex link between meteorological and physiological parameters that played a major role in the dynamic changes in MTS activities, storage pools and monoterpene emissions. For both years, the variation in the data could be fairly well described by two main factors: seasonality (principal component 1, PC1) and needle aging (principal component 2, PC2), which together accounted for $60 \%$ (2009) and $54 \%$ (2010) of the total variation in the dataset (Fig. 5). This was indicated by the clear separation in PC1 of summer (Fig. 5a-b, depicted in red), spring (in white) and autumn (in grey) samples for both 2008 and 2009 needle samples, and by the separation made by PC2 of 2008 needle samples (triangles) from 2009 needle samples (circles) (Fig. 5a-b). Meteorological and physiological data, in particular air temperatures, carbon assimilation, transpiration and needle growth rates, correlated positively with the monoterpene emission rates and negatively with MTS activities (Fig. 5c-d). Within the same year, the MTS activities were significantly and positively correlated with younger needles, and high monoterpene emissions with summer samples (Fig. 5a-d). In 2009, the endogenous monoterpene content was lower in young needles compared to the content in mature needles. Such a difference was absent in 2010, when both needle age classes were already mature, i.e. two and three years old, respectively.

Taken together, the multivariate data analysis revealed a seasonal and ontogenesis-related dependency of emissions, storage and biosynthesis of monoterpenes. Changes in both MTS activity and the monoterpene pool size were related to 

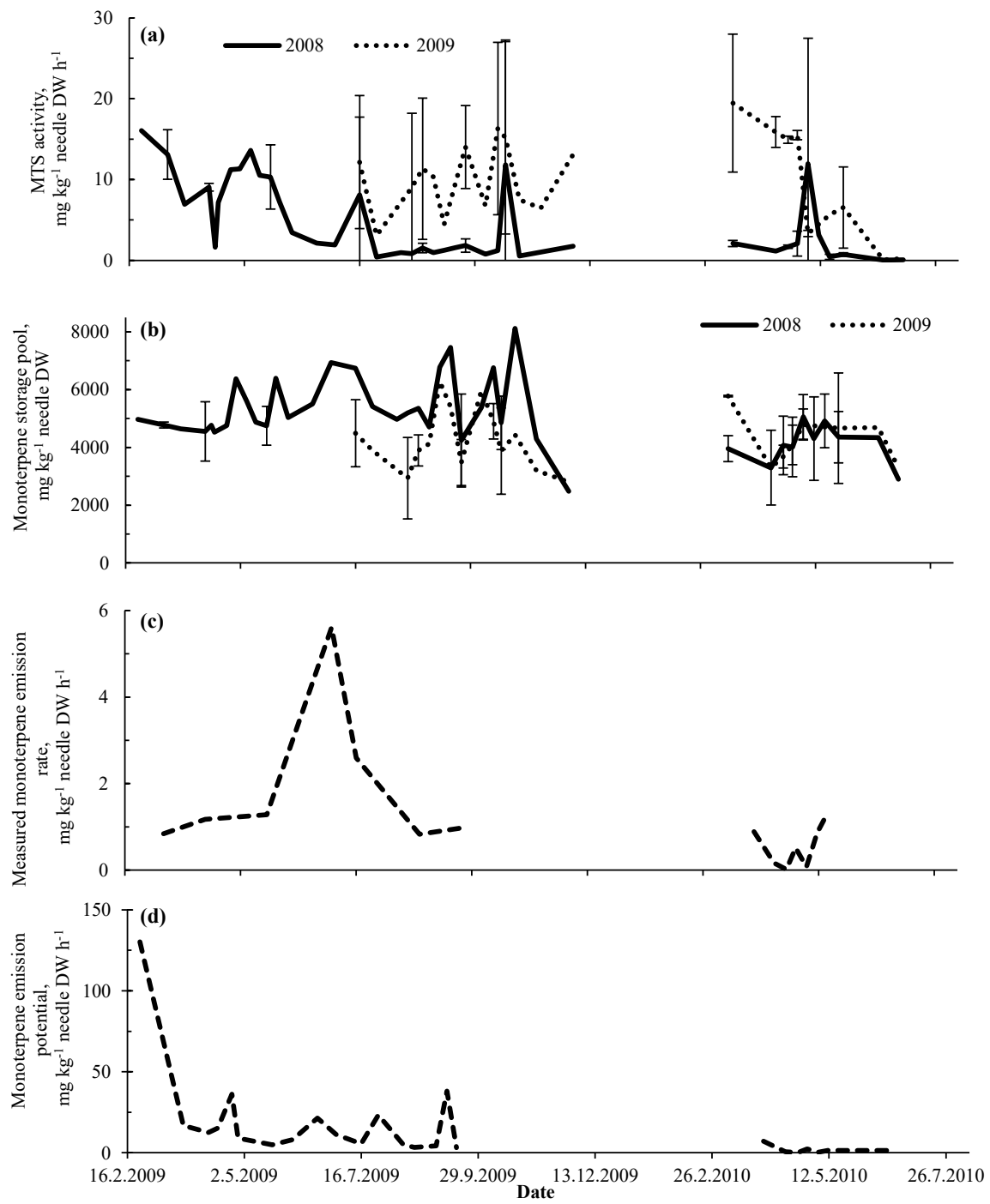

Figure 3. The synthase activities of $\alpha$-pinene, $\beta$-pinene, camphene and $\delta$-3-carene (sum, a), the storage pools of the same compounds (sum, b), their measured emission rates (sum, c) and emission potentials (standardized to $30^{\circ} \mathrm{C}$ ) (sum, d) as functions of time. In (a) and (b), the curves show the means \pm 1 standard deviation of the samples of different needle age classes (grown in 2008 and 2009) collected from trees \#3 and \#4. Missing error bars represent the dates when data were only available from one tree. In (c) and (d), the emissions originate from a shoot of tree \#3.

needle ontogenetic phases. These changes notably occurred during needle development and needle maturation, and were also affected by seasonality.

\subsection{Tree-to-tree variation}

Aiming at analysing the different tree chemotypes, we took needle samples twice from all the four trees that had initially been screened for the monoterpene blend in the emissions, and analysed the MTS activity, storage pools and emissions (only once) from the individual trees from the youngest needle year class (when the needles were 2 and 9 months old). The MTS activity varied between the trees: it was lowest in needles from tree \#2 in both summer and winter, and high- est in needles from tree \#4 in spring ( $>4$ times higher than in tree \#2) (Fig. 6a-b). The storage pool size was relatively stable across all trees and sampling times (Fig. 6c-d). In all four trees, $\alpha$-pinene was the most abundant monoterpene in the enzyme assay. The proportions of the four main monoterpenes changed little in both MTS assays and in storage pools between summer (August-September) and winter (March) in a given tree (Fig. 6a-d). However, a qualitative tree-specific difference was detected among the stored monoterpenes: the proportion of $\delta$-3-carene was pronounced (comprising 30$50 \%$ of the total monoterpenes) in the storage pools in trees \#2 to \#4 (Fig. 6c-d), whereas it was almost absent from the enzymatic monoterpene pattern of these trees (Fig. 6a-b). 

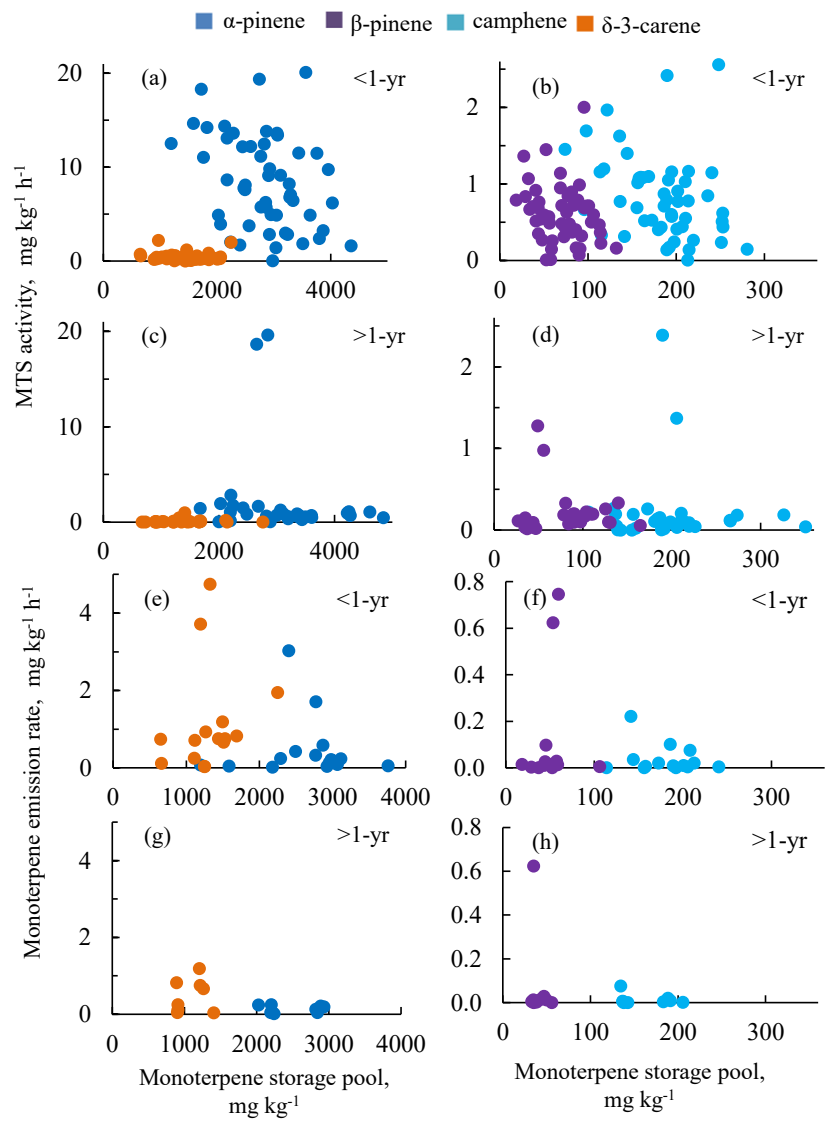

Figure 4. Relationship between monoterpene storage pools ( $x$ axes) and MTS activities (a-d) and between monoterpene emissions (eh) in $<1$-year-old (a, b, e, f) and >1-year-old (c, d, $\mathbf{g}, \mathbf{h})$ needles. Plots for more abundant compounds ( $\alpha$-pinene and $\delta$-3-carene) on the left and for less abundant compounds ( $\beta$-pinene and camphene) on the right. Emissions originated from both $<1$-year-old and $>1$ year-old needles and a twig. Data from trees \#3 and \#4.

Furthermore, in tree \#1, $\delta$-3-carene was completely missing from both MTS and storage.

The trees differed strongly in their monoterpene emission patterns (Fig. 6e). All trees emitted $\delta$-3-carene, but it was most dominant $(52 \%)$ in tree \#2, which also emitted high quantities $(31 \%)$ of $\beta$-pinene and had the highest emission rate in August. Tree \#1 dominantly emitted $\alpha$-pinene (74\% of overall monoterpene emissions), while this compound contributed only $17 \%, 24 \%$ and $35 \%$ to the emission pattern in trees \#2, \#3 and \#4, respectively. Thus, tree \#1 was classified as a clear "pinene chemotype", while the other three trees were "intermediate emitter types" (see Bäck et al., 2012). Interestingly, absolute monoterpene emission rates also varied considerably between the individual trees (Fig. 6e), although the temperatures in 2009 during the sampling period did not vary by more than a few degrees, other conditions did not differ, and no visible damage was seen in sampled branches. The variation in the standard emission factors for the four trees (\#1-4) was large, ranging from 3.2 (tree \#3) to 119 (\#2) $\mathrm{mg} \mathrm{kg}^{-1} \mathrm{DW} \mathrm{h}^{-1}$.

\section{Discussion}

Although the seasonal variations in monoterpene emissions from evergreen trees are well documented (e.g. Komenda and Koppmann, 2002; Tarvainen et al., 2005; Hakola et al., 2006), the reasons for this variation are poorly understood. The common explanation includes the temperature response of emissions, due to the strong role of temperature in physical parameters such as volatility and diffusion (e.g. Guenther, 1997; Niinemets and Reichstein, 2003a, b). This indeed creates seasonal dynamics, which partially but not fully explain the observed emission rates. The present results showed that the potentials to synthetize monoterpene, i.e. enzyme activities, are strongly dependent on needle age and season. However, these monoterpene synthase activities did not correlate with needle emission rates, and neither did the storage pool dynamics, which were virtually constant throughout the field experiment.

As indicated by the PCA analysis, the interaction between monoterpene synthesis, storage and emissions is complex and dependent on climatic factors (season) and needle age. Therefore, changes in emission rates at the leaf scale are probably a consequence of much more complex mechanisms than a simple incident temperature proxy (Aalto et al., 2014). This signifies the need to understand the physiological drivers, in addition to the physico-chemical drivers behind emissions.

The possible relationships between monoterpene production, storage and emissions were investigated in this study using simultaneous measurements of enzyme activities, storage pools and emissions. The results indicate that synthesis, emission rates and storage are mainly decoupled. For instance, high MTS activities did not correspond to large storage pools or high emission rates, while high emissions were not a result of large storage pools. The likely reasons for this are, on one hand, the large monoterpene storage pools in needles, and on the other hand, the disparity and time lags between production and emissions. Here, we see an analogy with VOC synthesis in Lamiaceae: during their early ontogenetic development, synthases actively produce volatiles in leaf glands, but biosynthesis slows down once storage pools in the glands are full (e.g. McConkey et al., 2000).

Our results demonstrate that the monoterpene storage pool can make up ca. $0.2 \%-0.8 \%$ of needle dry weight. These concentrations are in a similar range to previous observations from other conifers (Lerdau et al., 1997; Litvak and Monson, 1998; Litvak et al., 2002; Kännaste et al., 2013). Since emissions were 3 orders of magnitude less than pool sizes, they are unlikely to affect the pool sizes in the short to medium term. Similarly, the effect of MTS activities on pool sizes is also quite minimal in mature needles and in the 


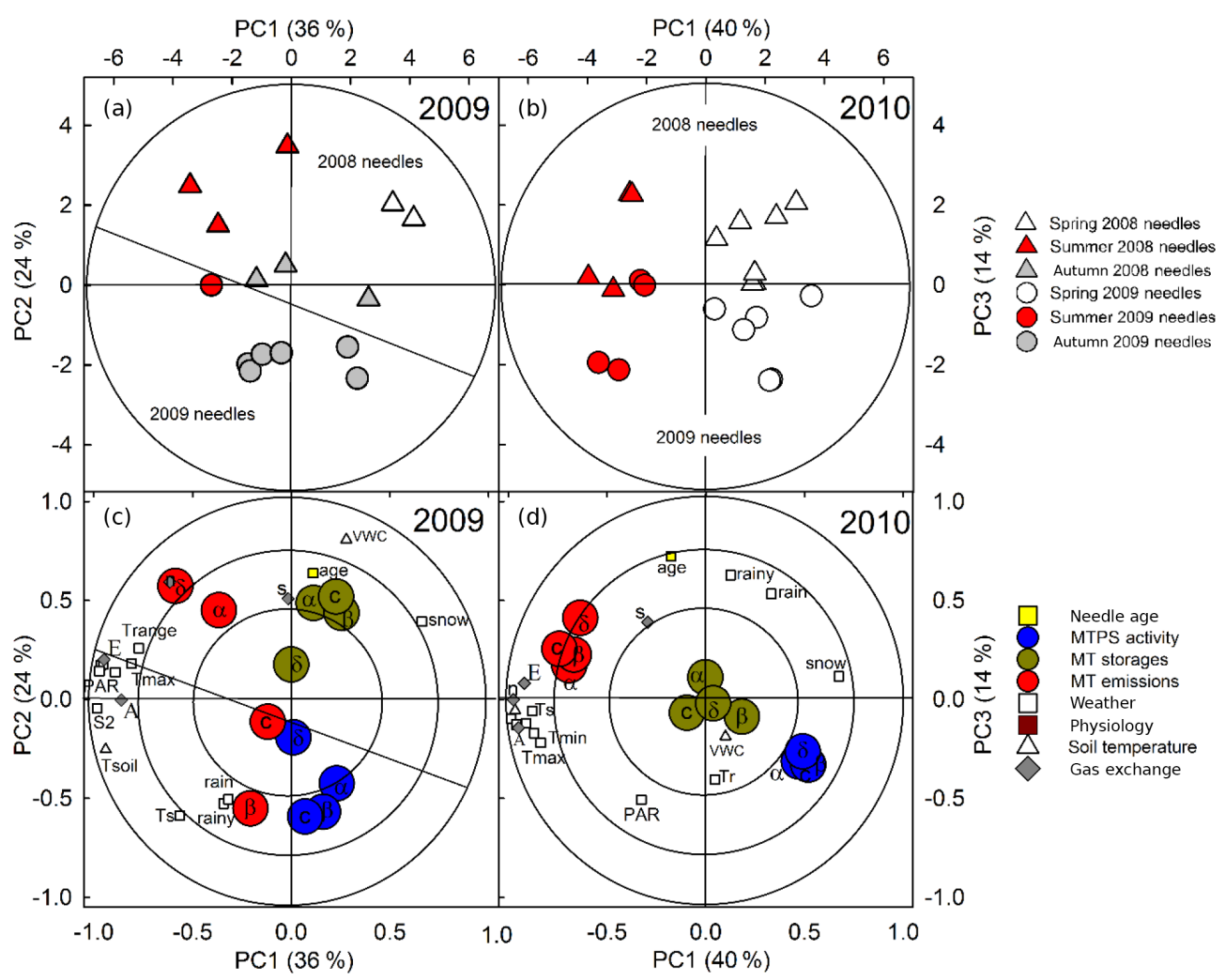

Figure 5. Two-dimensional (a-b) score plots and (c-d) scaled and centred loading plots of the PCA from monoterpene synthase activities, storage pools, emissions, and meteorological and physiological data collected in 2009 and 2010, respectively. Calculated significant principal components were validated using "full cross-validation", with the $99 \%$ confidence levels of parameters (with seven cross-validation groups). The explained variance (as a percentage) and the number of the principal component are given in both $x$ and $y$ axes. The ellipses in (a) and (b) indicate the tolerance based on Hotelling's $T^{2}$ with a significance level of 0.05 . From outer to inner, the three circles in (c) and (d) indicate $100 \%, 75 \%$ and $50 \%$ explained variance, respectively. Lines in (a) and (c) have additionally been added to indicate the borders between the 2008 and 2009 needle samples and their respective variables. Symbol legend (a-b): spring 1 March-15 May (white symbols), summer 16 May-14 August (red) and autumn 15 August-30 October (grey). The 2008 and 2009 needle samples are depicted with triangles and circles, respectively. $\alpha$ refers to $\alpha$-pinene, $\beta$ to $\beta$-pinene, (c) to camphene and $\delta$ to $\delta$-3-carene. The other variables are listed in Table 2 .

short term; thus, it did not show up in any correlations. It is known that incident monoterpene emissions simultaneously originate from previously filled and specialized storage pools and from de novo synthesis. In Scots pine, de novo synthesis can contribute $\sim 60 \%$ of the total emissions (Ghirardo et al., 2010), although this percentage must depend on both the rate of de novo production, which is light and temperature dependent and under the control of enzyme activities, and the magnitude of the emission rates from storage pools, which are only temperature dependent (Ghirardo et al., 2010; Loreto and Schnitzler, 2010). Changes in de novo biosynthesis can be expected to vary under different environmental conditions and, in light of the actual results for enzyme activities, follow seasonal and needle-age dependencies. Consistently, recent findings from the needles of field-grown Scots pines indicate that the ratio of de novo to storage pool emissions is not stable, but varies considerably in spring during photosynthetic recovery (Aalto et al., 2015). Our results, which indicate high
MTS activity in young developing needles, support this observation of highly dynamic biosynthesis.

The decoupling between monoterpene production and storage pools and emissions was also qualitatively evident: the individual MTS activities did not reflect the monoterpene composition found in the storage pool or in the shoot emission. For instance, $\delta$-3-carene was the second most abundant component in storage pools and also very prominent in emissions, but appeared in much smaller quantities than $\alpha$-pinene in the MTS activity. Similar decoupling of $\delta$-3-carene has also been found in ponderosa pine (Pinus ponderosa) (Harley et al., 2014).

The overall variation in the dataset was best correlated with the season and needle age, as indicated in the PCA analysis. Young needles generally displayed a larger emission capacity than older ones, reflected in their higher MTS activities. Our data indicate that needles retain a high capacity for monoterpene synthesis throughout their first full year of growth, but the MTS activity later sharply declines. 

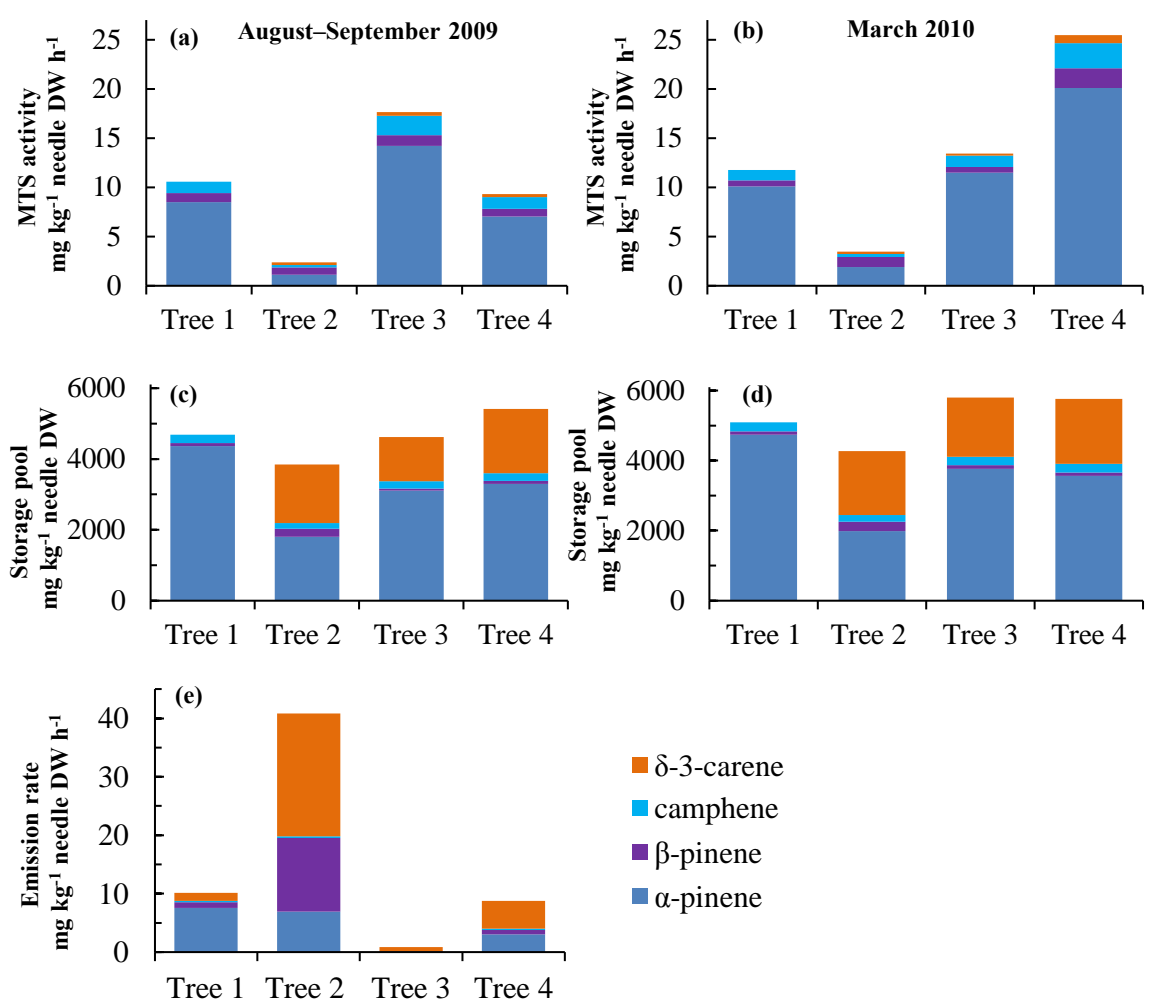

Figure 6. (a, b) Tree-to-tree variation for 2009 needles in monoterpene synthase activity and (c) and (d) monoterpene storage in late summer/autumn (August-September 2009: a, c, e approx. two-month-old needles) and in early spring (March 2010: b, d approx. nine-month-old needles). (e) Monoterpene emission rates were measured from all the trees studied in August 2009.

The monoterpene concentrations and the relative proportions in Scots pine needles are known to change during the first months of new needles (Thoss et al., 2007), and even though our data do not cover the very first months of needle development, our results support this observation. In particular, the $\delta$-3-carene dynamics appeared to be strongly related to needle age: this compound was synthesized in greater amounts in the needles only during their growth and maturation. In developing needles of trees \#3 and \#4, $\delta$-3-carene contributed $11 \%-19 \%$ to the total MTS activity, but the percentage declined during the following autumn to a level below the detection limit and remained at this level in older needles. This enzyme activity was sufficient to fill and sustain the storage pools: the corresponding proportions of $\delta$-3-carene in monoterpene storage pools of the new needles in trees \#3 and \#4 were $38 \%-42 \%$, and later in autumn $27 \%-34 \%$. Thoss et al. (2007) also reported a developmental response such as this for $\delta$-3-carene for the first three months after needle emergence. Interestingly, $\delta$-3-carene has been considered as the least toxic monoterpene to bark beetles and their associated fungi (Raffa et al., 2014; Reid et al., 2017). This suggests that the abundance or scarcity of $\delta$-3-carene (i.e. the pine chemotype) could play a key role in the interactions between pines and other organisms.
The stability of the storage pool suggests that the monoterpene storages are filled during the very first weeks or months after leaf emergence (Bernard-Dagan, 1988; Schönwitz et al., 1990). This is logical when considering that one of the main reasons for storing monoterpenes in needles is their protection from herbivory (Langenheim, 1994; Litvak and Monson, 1998; Loreto et al., 2000a), and the youngest needles are particularly susceptible to many insects feeding on the fresh, sugar-rich tissues. This is also in line with the higher MTS activity in the youngest needles.

Our data suggest that the turnover of the permanent storage is a very slow process, and agree with the low rate of incorporation of ${ }^{13} \mathrm{C}$ into the storage pool observed after $8 \mathrm{~h}$ of ${ }^{13} \mathrm{CO}_{2}$ labelling in Scots pine seedlings (Ghirardo et al., 2010). Earlier, no variations were found in the monoterpene storage composition between different age classes or between seasons in the case of mature Scots pine needles (Thoss et al., 2007). Some monoterpenes may also accumulate in needle surface waxes (Joensuu et al., 2016; Despland et al., 2016). However, needle wax is probably a rather shortterm monoterpene storage and may not have a major impact on the incident emission rates, at least for the main emitted compounds. 
The time lag between monoterpene synthesis and emissions can probably range from minutes (de novo) to days (permanent pools). The MTS activities could possibly correlate with de novo emissions in the short term, but this cannot be addressed with our data, which were collected at approximate bi-weekly intervals. A much finer temporal resolution and labelling experiments should be used to analyse the relationships further. In addition, it is evident that the in vitro synthase activities we measured here reflect the maximum potential of the needle tissue to synthesize monoterpenes under optimal conditions of temperature, $\mathrm{pH}$ and saturated substrate availability. Thus, they may not represent in situ synthesis processes, and this is a possible reason for the observed decoupling of production and storage/emissions.

Together with the synthase activities, the monoterpene precursor (substrate) availability is involved in monoterpene production. Monoterpene biosynthesis relies on photosynthesis for the supply of carbon substrates, reductive (reduced form of nicotinamide adenosine dinucleotide phosphate, NADPH) and energetic equivalents (adenosine triphosphate, ATP) (Lichtenthaler et al., 1997; Phillips et al., 2008). The impact of substrate availability on enzyme reaction can vary largely, depending on the pool size of the substrate and the velocity of the enzyme to catalyze its reaction. Isoprene production is known to be under the control of both precursors and enzyme activities (Rasulov et al., 2010). Theoretically, monoterpene emissions are expected to be much more "sensitive" to enzyme activities than substrate limitation due to the much lower Michaelis-Menten constant $\left(K_{\mathrm{m}}\right)$ of the MTP synthases, i.e. the concentration of the substrate when the reaction velocity to produce the volatile is equal to one half of the maximal velocity for the reaction. $K_{\mathrm{m}}$ for MTP synthases is in the range of $3-67 \mu \mathrm{mol} \mathrm{L}^{-1}$ (Alonso and Croteau, 1991; Fischbach et al., 2000) while for isoprene synthase it is between 500 and $970 \mu \mathrm{mol} \mathrm{L}{ }^{-1}$ (e.g. Zimmer et al., 2000; Tholl et al., 2001; Wolfertz et al., 2004). Following previous studies, the large pool of the monoterpene precursor geranyl diphosphate (GDP) is not likely to be the limiting factor of monoterpene emissions (Nogués et al., 2006) under such low $K_{\mathrm{m}}$ of the MTP synthase. This is valid at least until the photosynthesis is not impaired, as in the four trees of our study. However, realistic GDP pools in coniferous species (15-25 pmol mg ${ }^{-1}$, Ghirardo et al., 2010) are also relatively low compared to the isoprene precursor dimethylallyl diphosphate (DMADP) found in the plastids of isoprene emitting plants $\left(33-50 \mathrm{pmol} \mathrm{mg}^{-1}\right.$, data derived from Ghirardo et al., 2014). Therefore, strong changes of the GDP pools occurring during seasonal and temperature changes (Nogués et al., 2006) are likely to have affected the link between substrate and monoterpene emissions to some extent. Although we have studied the major factor controlling the monoterpene emissions (i.e. the enzyme activity), the unexplored substrate availability may play a role in the decoupling of production and storage/emissions and explains some of the variability observed among individual trees.
As we aimed at a measurement set-up with repeated samplings, the challenge was to keep the extremely delicate monoterpene storage pools as intact as possible and to avoid any induced emission responses (Ghirardo et al., 2010; Niinemets et al., 2011). However, the monoterpene synthase activities varied between and within trees, and some days with exceptionally high MTS activities and emissions were observed. They may be due to certain short-term processes such as transient responses to herbivory or mechanical stress. It is known that handling a pine shoot causes increased monoterpene emissions for a few days (Ruuskanen et al., 2005). In addition, the observed anomalous emission blend of tree \#3 in September 2009 could have originated from a stress reaction, and such unexplained high emission peaks have also been reported earlier in similar measurement set-ups (e.g. Tarvainen et al., 2005). Nevertheless, no visible damage was observed in the needles prior to sampling, and the twigs were not mechanically injured.

Furthermore, we collected the first set of youngest needles in mid-July, at a time when shoot lignification had not been fully completed and needle elongation was still in progress (ca. $85 \%$ of final length, see Fig. 2). In practice, sampling short shoots before their lignification is already advanced causes large wounds and ample resin flow from the wounded twig.

One caveat in the emission measurement method is that the enclosures contained needles from two older year classes, but did not contain the youngest (2009) needles. Thus, we cannot separate the effect of needle development and maturation from this dataset: almost all emission measurements were performed from already mature needles, and only a fraction of the emissions originated from $<1$-year-old needles in the spring and summer of 2009. A part of the emissions may also have originated from non-needle sources, i.e. the woody tissues of twigs.

This study was the first known research to address the relationship between monoterpene synthase activities, storage pools and emissions in situ in a resin-storing conifer, Scots pine. Our results emphasize the seasonal dynamics and developmental and intraspecific variability in monoterpene biosynthesis and storage, and call for more studies to reveal their connections with emission rates. As the monoterpene emissions depend on physiological, structural and environmental factors as well as on plant chemotypes in a complex manner, future studies should focus more attention on describing the seasonality as well as the tree-to-tree variation, by using a sufficient number of measurements and plant individuals. Also, the availability of the substrate GDP and its potential impact on monoterpene emissions should preferably be included in following studies. To improve the mathematical models for an accurate prediction of monoterpene emissions from boreal regions, a better understanding of the complex linkage between all the factors controlling monoterpene emission is urgently needed. 
Data availability. The weather data measured at the SMEAR II station are available on the following website: http://avaa.tdata.fi/web/ smart/ (last access: 30 September 2017; Junninen et al., 2009). The data is licensed under a Creative Commons 4.0 Attribution (CC BY) license. The other datasets (monoterpenes, physiological data etc.) can be obtained from the corresponding author upon request.

Competing interests. The authors declare that they have no conflict of interest.

Acknowledgements. We thank Juho Aalto and Janne Korhonen for assisting with sample collection and data analysis. The SMEAR II staff are acknowledged for their maintenance of the measurements and infrastructure.

This work was supported by the Academy of Finland Centre of Excellence programme [1118615 and 272041], the Helsinki University Centre for Environment HENVI [470149021], the Nordic Centre of Excellence CRAICC and the COST Action FP0903 "Climate Change and Forest Mitigation and Adaptation in a Polluted Environment".

Edited by: Akihiko Ito

Reviewed by: two anonymous referees

\section{References}

Aalto, J., Kolari, P., Hari, P., Kerminen, V.-M., Schiestl-Aalto, P., Aaltonen, H., Levula, J., Siivola, E., Kulmala, M., and Bäck, J.: New foliage growth is a significant, unaccounted source for volatiles in boreal evergreen forests, Biogeosciences, 11, 13311344, https://doi.org/10.5194/bg-11-1331-2014, 2014.

Aalto, J., Porcar-Castell, A., Atherton, J., Kolari, P., Pohja, T., Hari, P., Nikinmaa, E., Petäjä, T., and Bäck, J.: Onset of photosynthesis in spring speeds up monoterpene synthesis and leads to emission bursts, Plant Cell Environ., 38, 2299-2312, 2015.

Alonso, W. R. and Croteau, R.: Purification and characterization of the monoterpene cyclase $\gamma$-terpinene synthase from Thymus vulgaris, Arch. Biochem. Biophys., 286, 511-517, 1991.

Altimir, N., Kolari, P., Tuovinen, J.-P., Vesala, T., Bäck, J., Suni, T., Kulmala, M., and Hari, P.: Foliage surface ozone deposition: a role for surface moisture?, Biogeosciences, 3, 209-228, https://doi.org/10.5194/bg-3-209-2006, 2006.

Bernard-Dagan, C.: Seasonal variations in energy sources and biosynthesis of terpenes in maritime pine, in: Mechanisms of woody plant defenses against insects, edited by: Mattson, W. J., Levieux, J., and Bernard-Dagan, C., Springer, New York, USA, 93-116, 1988.

Bäck, J., Aalto, J., Henriksson, M., Hakola, H., He, Q., and Boy, M.: Chemodiversity of a Scots pine stand and implications for terpene air concentrations, Biogeosciences, 9, 689-702, https://doi.org/10.5194/bg-9-689-2012, 2012.

Bohlmann, J., Meyer-Gauen, G., and Croteau, R.: Plant terpenoid synthases: Molecular biology and phylogenetic analysis, P. Natl. Acad. Sci. USA, 95, 4126-4133, 1998.
Despland, E., Bourdier, T., Dion, E., and Bauce, E.: Do white spruce epicuticular wax monoterpenes follow foliar patterns?, Can. J. Forest Res., 46, 1051-1058, 2016.

Dudareva, N., Pichersky, E., and Gershenzon, J.: Biochemistry of plant volatiles, Plant Physiol., 135, 1893-1902, 2004.

Ensminger, I., Sveshnikov, D., Campbell, D. A., Funk, C., Jansson, S., Lloyd, J., Shibistova, O., and Öquist, G.: Intermittent low temperatures constrain spring recovery of photosynthesis in boreal Scots pine forests, Glob. Change Biol., 10, 995-1008, 2004.

Ensminger, I., Busch, F., and Huner, N. P. A.: Photostasis and cold acclimation: sensing low temperatures through photosynthesis, Physiol. Plant, 126, 28-44, 2006.

Fischbach, R. J., Zimmer, I., Steinbrecher, R., Pfichner, A., and Schnitzler, J.-P.: Monoterpene synthase activities in leaves of Picea abies (L.) Karst and Quercus ilex L., Phytochem, 54, 257265, 2000.

Fischbach, R. J., Staudt, M., Zimmer, I., Rambal, S., and Schnitzler, J.-P.: Seasonal pattern of monoterpene synthase activities in leaves of the evergreen tree Quercus ilex, Physiol. Plant, 114, 354-360, 2002.

Ghirardo, A., Koch, K., Taipale, R., Zimmer, I., Schnitzler, J.-P., and Rinne, J.: Determination of de novo and pool emissions of terpenes from four common boreal/alpine trees by ${ }^{13} \mathrm{CO}_{2}$ labelling and PTR-MS analysis, Plant Cell Environ., 33, 781-792, 2010.

Ghirardo, A., Gutknecht, J., Zimmer, I., Brüggemann, N., and Schnitzler, J.-P.: Biogenic volatile organic compound and respiratory $\mathrm{CO}_{2}$ emissions after ${ }^{13} \mathrm{C}$-labeling: online tracing of $\mathrm{C}$ translocation dynamics in poplar plants, PLoS ONE, 6, e17393, https://doi.org/10.1371/journal.pone.0017393, 2011.

Ghirardo, A., Heller, W., Fladung, M., Schnitzler, J.-P., and Schroeder, H.: Function of defensive volatiles in pedunculate oak (Quercus robur) is tricked by the moth Tortrix viridana, Plant Cell Environ., 35, 2192-2207, 2012.

Ghirardo, A., Wright, L. P., Bi, Z., Rosenkranz, M., Pulido, P., Rodríguez-Concepción, M., Niinemets, Ü., Brüggemann, N., Gershenzon, J., and Schnitzler, J.-P.: Metabolic flux analysis of plastidic isoprenoid biosynthesis in poplar leaves emitting and non-emitting isoprene, Plant Physiol., 165, 37-51, 2014.

Guenther, A.: Seasonal and spatial variations in natural volatile organic compound emissions, Ecol. Appl., 7, 34-45, 1997.

Hakola, H., Tarvainen, V., Bäck, J., Ranta, H., Bonn, B., Rinne, J., and Kulmala, M.: Seasonal variation of mono- and sesquiterpene emission rates of Scots pine, Biogeosciences, 3, 93-101, https://doi.org/10.5194/bg-3-93-2006, 2006.

Hakola, H., Tarvainen, V., Praplan, A. P., Jaars, K., Hemmilä, M., Kulmala, M., Bäck, J., and Hellén, H.: Terpenoid and carbonyl emissions from Norway spruce in Finland during the growing season, Atmos. Chem. Phys., 17, 3357-3370, https://doi.org/10.5194/acp-17-3357-2017, 2017.

Hari, P. and Kulmala, M.: Station for Measuring EcosystemAtmosphere Relations (SMEAR II), Boreal Environ. Res., 10, 315-322, 2005.

Harley, P., Eller, A., Guenther, A., and Monson, R. K.: Observations and models of emissions of volatile terpenoid compounds from needles of ponderosa pine trees growing in situ: control by light, temperature and stomatal conductance, Oecologia, 176, 35-55, 2014. 
Hellén, H., Kuronen, P., and Hakola, H.: Heated stainless steel tube for ozone removal in the ambient air measurements of mono- and sesquiterpenes, Atmos. Environ., 57, 35-40, 2012.

Hänninen, H. and Tanino, K.: Tree seasonality in a warming climate, Trends Plant Sci., 16, 412-416, 2011.

Ilvesniemi, H., Levula, J., Ojansuu, R., Kolari, P., Kulmala, L., Pumpanen, J., Launiainen, S., Vesala, T., and Nikinmaa, E.: Long-term measurements of the carbon balance of a boreal Scots pine dominated forest ecosystem, Boreal Environ. Res., 14, 731753, 2009

Jaakola, L. and Hohtola, A.: Effect of latitude on flavonoid biosynthesis in plants, Plant Cell Environ., 33 1239-1247, 2010.

Janson, R.: Monoterpene emissions from Scots pine and Norwegian spruce, J. Geophys. Res.-Atmos., 98, 2839-2850, 1993.

Joensuu, J., Altimir, N., Hakola, H., Rostás, M., Raivonen, M., Vestenius, M., Aaltonen, H., Riederer, M., and Bäck, J.: Role of needle surface waxes in dynamic exchange of mono- and sesquiterpenes, Atmos. Chem. Phys., 16, 7813-7823, https://doi.org/10.5194/acp-16-7813-2016, 2016.

Junninen, H., Lauri, A., Keronen, P., Aalto, P., Hiltunen, V., Hari, P., and Kulmala, M.: Smart-SMEAR: on-line data exploration and visualization tool for SMEAR stations, Boreal Environ. Res., 14, 447-457, 2009.

Komenda, M. and Koppmann, R.: Monoterpene emissions from Scots pine (Pinus sylvestris): Field studies of emission rate variabilities, J. Geophys. Res., 107, 4161, https://doi.org/10.1029/2001JD000691, 2002.

Kreuzwieser, J., Scheerer, U., Kruse, J., Burzlaff ,T., Honsel, A., Alfarraj, S., Georgiev, P., Schnitzler, J.-P., Ghirardo, A., Kreuzer, I., Hedrich, R., and Rennenberg, H.: The Venus flytrap attracts insects by the release of volatile organic compounds, J. Exp. Bot., 65, 755-766, 2014.

Kännaste, A., Copolovici, L., Pazouki, L., Suhhorutšenko, M., and Niinemets, Ü.: Highly variable chemical signatures over short spatial distances among Scots pine (Pinus sylvestris) populations, Tree Phys., 33, 374-387, 2013.

Langenheim, J. H.: Higher plant terpenoids: a phytocentric overview of their ecological roles, J. Chem. Ecol., 20, 12231280, 1994.

Lerdau, M., Litvak, M., Palmer, P., and Monson, R.: Controls over monoterpene emissions from boreal forest conifers, Tree Phys., 17, 563-569, 1997.

Lichtenthaler, H. K., Rohmer, M., and Schwender, J.: Two independent biochemical pathways for isopentenyl diphosphate and isoprenoid biosynthesis in higher plants, Physiol. Plantarum, 101, 643-652, 1997.

Litvak, M. E. and Monson, R. K.: Patterns of induced and constitutive monoterpene production in conifer needles in relation to insect herbivory, Oecologia, 114, 531-540, 1998.

Litvak, M. E., Constable, J. V. H., and Monson, R. K.: Supply and demand processes as controls over needle monoterpene synthesis and concentration in Douglas fir [Pseudotsuga menziesii (Mirb) Franco], Oecologia, 132, 382-391, 2002.

Llusià, J., Peñuelas, J., Alessio, G. A., and Estiarte, M.: Seasonal contrasting changes of foliar concentrations of terpenes and other volatile organic compound in four dominant species of a Mediterranean shrubland submitted to a field experimental drought and warming, Physiol. Plant, 127, 632-649, 2006.
Loreto, F. and Schnitzler, J.-P.: Abiotic stresses and induced BVOCs, Trends Plant Sci., 15, 154-166, 2010.

Loreto, F. and Velikova, V.: Isoprene produced by leaves protects the photosynthetic apparatus against ozone damage, quenches ozone products, and reduces lipid peroxidation of cellular membranes, Plant Physiol., 127, 1781-1787, 2001.

Loreto, F., Nascetti, P., Graverini, A., and Mannozzi, M.: Emission and content of monoterpenes in intact and wounded needles of the Mediterranean pine, Pinus pinea, Funct. Ecol., 14, 589-595, 2000a.

Loreto, F., Ciccioli, P., Brancaleoni, E., Frattoni, M., and Delfine, S.: Incomplete ${ }^{13} \mathrm{C}$ labelling of $\alpha$-pinene content of Quercus ilex leaves and appearance of unlabelled $\mathrm{C}$ in $\alpha$-pinene emission in the dark, Plant Cell Environ., 23, 229-234, 2000b.

McConkey, M. E., Gershenzon, J., and Croteau, R. B.: Developmental regulation of monoterpene biosynthesis in the glandular trichomes of peppermint, Plant Physiol., 122, 215-233, 2000.

Mäkelä, A., Hari, P., Berninger, F., Hänninen, H., and Nikinmaa, E.: Acclimation of photosynthetic capacity in Scots pine to the annual cycle of temperature, Tree Phys., 24, 369-378, 2004.

Niinemets, Ü. and Reichstein, M.: A model analysis of the effects of nonspecific monoterpenoid storage in leaf tissues on emission kinetics and composition in Mediterranean sclerophyllous Quercus species, Global Biogeochem. Cy., 16, 1-26, 2002.

Niinemets, Ü. and Reichstein, M.: Controls on the emission of plant volatiles through stomata: Differential sensitivity of emission rates to stomatal closure explained, J. Geophys. Res., 108, 4208, https://doi.org/10.1029/2002JD002620, 2003a.

Niinemets, Ü. and Reichstein, M.: Controls on the emission of plant volatiles through stomata: A sensitivity analysis, J. Geophys. Res., 108, 4211, https://doi.org/10.1029/2002JD002626, 2003 b.

Niinemets, Ü., Kuhn, U., Harley, P. C., Staudt, M., Arneth, A., Cescatti, A., Ciccioli, P., Copolovici, L., Geron, C., Guenther, A., Kesselmeier, J., Lerdau, M. T., Monson, R. K., and Peñuelas, J.: Estimations of isoprenoid emission capacity from enclosure studies: measurements, data processing, quality and standardized measurement protocols, Biogeosciences, 8, 2209-2246, https://doi.org/10.5194/bg-8-2209-2011, 2011.

Nogués, I., Brilli, F., and Loreto, F.: Dimethylallyl diphosphate and geranyl diphosphate pools of plant species characterized by different isoprenoid emissions, Plant Physiol., 141, 721-730, 2006.

Ormeño, E., Goldstein, A., and Niinemets, Ü.: Extracting and trapping biogenic volatile organic compounds stored in plant species, Trend. Anal. Chem., 30, 978-989, 2011.

Owen, S. M. and Penũelas, J.: Opportunistic emissions of volatile isoprenoids, Trends Plant Sci., 10, 420-426, 2005.

Phillips, M. A., D’Auria, J. C., Gershenzon, J., and Pichersky, E.: The Arabidopsis thaliana type I Isopentenyl Diphosphate Isomerases are targeted to multiple subcellular compartments and have overlapping functions in isoprenoid biosynthesis, Plant Cell Environ., 20, 677-696, 2008.

Pirinen, P., Simola, H., Aalto, J., Kaukoranta, J.-P., Karlsson, P., and Ruuhela, R.: Tilastoja Suomen ilmastosta 1981-2010 [Climatological statistics of Finland 1981-2010], Finnish Meteorological Institute Reports, 1, 1-96, 2012.

Porcar-Castell, A., Juurola, E., Nikinmaa, E., Ensminger, I., Berninger, F., and Hari, P.: Seasonal acclimation of photosystem II in Pinus sylvestris. I. Estimating the rate constants of sustained 
heat dissipation and photochemistry, a new tool to complement Fv/Fm, Tree Phys., 28, 1475-1482, 2008.

Raffa, K.: Terpenes tell different tales at different scales: glimpses into the chemical ecology of conifer - bark beetle - microbial interactions, J. Chem. Ecol., 40, 1-20, 2014.

Rasulov, B., Hüve, K., Bichele, I., Laisk, A., and Niinemets, Ü.: Temperature response of isoprene emission in vivo reflects a combined effect of substrate limitations and isoprene synthase activity: a kinetic analysis, Plant Physiol., 154, 1558-1570, 2010.

Reid, M. L., Sekhon, J. K., and LaFramboise, L. M.: Toxicity of monoterpene structure, diversity and concentration to mountain pine beetles, Dendroctonus ponderosae: beetle traits matter more, J. Chem. Ecol., 43, 351-361, 2017.

Ruuskanen, T. M., Kolari, P., Bäck, J., Kulmala, M., Rinne, J., Hakola, H., Taipale, R., Raivonen, M., Altimir, N., and Hari, P.: On-line field measurements of monoterpene emissions from Scots pine by proton-transfer-reaction mass spectrometry, Boreal Environ. Res., 10, 553-567, 2005.

Schönwitz, R., Kloos, M., Merk, L., and Ziegler, H.: Patterns of monoterpenes stored in the needles of Picea abies (L.) Karst. from several locations in mountainous regions of southern Germany, Trees, 4, 27-33, 1990a.

Schönwitz, R., Lohwasser, K., Kloos, M., and Ziegler, H.: Seasonal variation in the monoterpenes in needles of Picea abies (L.) Karst, Trees, 4, 34-40, 1990b.

Tarvainen, V., Hakola, H., Hellén, H., Bäck, J., Hari, P., and Kulmala, M.: Temperature and light dependence of the VOC emissions of Scots pine, Atmos. Chem. Phys., 5, 989-998, https://doi.org/10.5194/acp-5-989-2005, 2005.

Tholl, D., Croteau, R., and Gershenzon, J.: Partial purification and characterization of the short-chain prenyltransferases, geranyl diphosphate synthase and farnesyl diphosphate synthase, from Abies grandis (grand fir), Arch. Biochem. Biophys., 386, 233242, 2001.

Thoss, V., O'Reilly-Wapstra, J., and Iason, G. R.: Assessment and implications of intraspecific and phenological variability in monoterpenes of Scots pine (Pinus sylvestris) foliage, J. Chem. Ecol., 33, 477-491, 2007.
Velikova, V., Ghirardo, A., Vanzo, E., Merl, J., Hauck, S. M., and Schnitzler, J.-P.: The genetic manipulation of isoprene emissions in poplar plants remodels the chloroplast proteome, J. Proteome Res., 13, 2005-2018, 2014.

Velikova, V., Müller, C., Ghirardo, A., Rock, T. M., Aichler, M., Walch, A., Schmitt-Kopplin, P., and Schnitzler, J.-P.: Knocking down of isoprene emission modifies the lipid matrix of thylakoid membranes and influences the chloroplast ultrastructure in poplar, Plant Physiol., 168, 859-870, 2015.

Vesala, T., Suni, T., Rannik, Ü., Keronen, P., Markkanen, P., Sevanto, S., Grönholm, T., Smolander, S., Kulmala, M., Ilvesniemi, H., Ojansuu, R., Uotila, A., Levula, J., Mäkelä, A., Pumpanen, J., Kolari, P., Kulmala, L., Altimir, N., Berninger, F., Nikinmaa, E., and Hari, P.: Effect of thinning on surface fluxes in a boreal forest, Global Biogeochem. Cy., 19, 1-11, 2005.

Wiß, F., Ghirardo, A., Schnitzler, J.-P., Nendel, C., Augustin, J., Hoffmann, M., and Grote, R.: Net ecosystem fluxes and composition of BVOCs over a maize field - Interaction of meteorology and phenological stages, GCB Bioenergy, 9, 1627-1643, 2017.

Wolfertz, M., Sharkey, T. D., Boland, W., and Kühnemann, F.: Rapid regulation of the methylerythritol 4-phosphate pathway during isoprene synthesis, Plant Physiol., 135, 1939-1945, 2004.

Wright, L. P., Rohwer, J. M., Ghirardo, A., Hammerbacher, A., Ortiz-Alcaide, M., Raguschke, B., Schnitzler, J.-P., Gershenzon, J., and Phillips, M.: Deoxyxylulose 5-phosphate synthase controls flux through the methylerythritol 4-phosphate pathway in Arabidopsis, Plant Physiol., 165, 1488-1504, 2014.

Zimmer, W., Brüggemann, N., Emeis, S., Giersch, C., Lehning, A., Steinbrecher, R., and Schnitzler, J.: Process-based modelling of isoprene emission by oak leaves, Plant Cell Environ., 23, 585595, 2000. 